\title{
Insecticide resistance status of Anopheles gambiae s.s population from M'Bé: a WHOPES-labelled experimental hut station, 10 years after the political crisis in Côte d'Ivoire
}

Alphonsine A Koffi ${ }^{1 *}$, Ludovic P Ahoua Alou ${ }^{1,2}$, Maurice A Adja ${ }^{1,2}$, Fabrice Chandre ${ }^{3}$ and Cédric Pennetier ${ }^{3,4^{*}}$

\begin{abstract}
Background: An experimental hut station built at M'Bé in 1998 was used for many years for the evaluation of insecticidal product for public health until the civil war broke out in 2002. Breeding sites of mosquitoes and selection pressure in the area were maintained by local farming practices and the West African Rice Development Association (WARDA, actually AfricaRice) in a large rice growing area. Ten years after the crisis, bioassays, molecular and biochemical analyses were conducted to update the resistance status and study the evolution of resistance mechanisms of Anopheles gambiae s.s population.

Methods: Anopheles gambiae s.s larvae from M'Bé were collected in breeding sites and reared until emergence. Resistance status of this population to conventional insecticides was assessed using WHO bioassay test kits for adult mosquitoes, with 10 insecticides belonging to pyrethroids, pseudo-pyrethroid, organochlorides, carbamates and organophosphates with and without the inhibitor piperonyl butoxyde (PBO). Molecular and biochemical assays were carried out to identify the L1014F $k d r$, L1014S $k d r$ and $a c e-1^{R}$ alleles in individual mosquitoes and to detect potential increase in mixed function oxidases (MFO) level, non-specific esterases (NSE) and glutathione S-transferases (GST) activities.
\end{abstract}

Results and discussion: Anopheles gambiae s.s from M'Bé exerted high resistance levels to organochlorides, pyrethroids, and carbamates. Mortalities ranged from 3\% to $21 \%$ for organochlorides, from $50 \%$ to $75 \%$ for pyrethroids, 34\% for etofenprox, the pseudo-pyrethroid, and from $7 \%$ to $80 \%$ for carbamates. Tolerance to organophosphates was observed with mortalities ranging from $95 \%$ to $98 \%$. Bioassays run with a pre-exposition of mosquitoes to PBO induced very high levels of mortalities compared to the bioassays without PBO, suggesting that the resistance to pyrethroid and carbamate relied largely on detoxifying enzymes' activities. The L1014F $k d r$ allelic frequency was 0.33 in 2012 compared to 0.05 before the crisis in 2002. Neither the L1014S kdr nor ace- $1^{R}$ mutations were detected. An increased activity of NSE and level of MFO was found relative to the reference strain Kisumu. This was the first evidence of metabolic resistance based resistance in An. gambiae s.s from M'Bé.

Conclusion: The An. gambiae s.s population showed very high resistance to organochlorides, pyrethroids and carbamates. This resistance level relied largely on two major types of resistance: metabolic and target-site mutation. This multifactorial resistance offers a unique opportunity to evaluate the impact of both mechanisms and their interaction with the vector control tools currently used or in development.

Keywords: Insecticide-resistance, Anopheles gambiae, M'Bé, Côte d'Ivoire

\footnotetext{
*Correspondence: koffi_alphonsine@yahoo.fr; cedric.pennetier@ird.fr 'Institut Pierre Richet (IPR), Abidjan BP 47, Côte d'Ivoire

${ }^{3}$ Institut de Recherche pour le Développement (IRD)/UMR224 MiVEGEC, Montpellier 34394, France

Full list of author information is available at the end of the article
}

\section{Biomed Central}

(c) 2013 Koffi et al.; licensee BioMed Central Ltd. This is an Open Access article distributed under the terms of the Creative Commons Attribution License (http://creativecommons.org/licenses/by/2.0), which permits unrestricted use, distribution, and reproduction in any medium, provided the original work is properly cited. 


\section{Background}

The scaling-up of long-lasting insecticidal nets (LLINs) and to some extent indoor residual spraying (IRS) is the cornerstone element of international strategies to control malaria transmission [1]. Four classes of chemical insecticides are the mainstay of vector control programmes [2], but pyrethroids are the only class of insecticide currently recommended for use on LLINs because of their irritant and fast-acting properties and their safety for humans [3]. Under the selective pressure of insecticides massively used in agriculture $[4,5]$ and also in public health programmes [6,7], pyrethroid resistance has become widespread among Anopheles gambiae s.l in sub-Saharan Africa [8-10]. Even in four insecticide classes available for IRS, resistance has been reported for all of them in some populations of Anopheles gambiae s.s [11]. Thus the arsenal for managing resistance and providing sustainable vector control with existing chemicals is becoming seriously limited.

Until alternative chemicals arise, manufacturers, national and international authorities bring their experiences together to build new strategies to manage insecticide resistance issues [12]. In this process the most advanced strategy is to combine two chemicals with different modes of action into one LLIN against malaria pyrethroidresistant vectors [13]. Since a decade, few combinations are under evaluation for resistance management: pyrethroids and organophosphates [14], repellents and organophosphates $[15,16]$, pyrrole insecticide and pyrethroid [17], pyrethroid and the synergist piperonyl butoxyde (PBO) [18-21]. The only combinations that has been manufactured into LLINs and submitted to WHO evaluation process are mosaic or mixture of $\mathrm{PBO}$ and pyrethroids (deltamethrin or permethrin).

The World Health Organization Pesticide Evaluation Scheme (WHOPES) reviews and makes recommendations on new pesticide technologies for public health programmes, such as LLINs or IRS. The WHOPES testing and evaluation process is divided into four phases: Phase I: the efficacy is investigated under laboratory conditions against standard (susceptible or insecticide resistant) mosquito strains; Phase II: the efficacy is investigated against wild vector populations in standardized field conditions (experimental huts); Phase III is a review of overall performance in the field at village scale; and, Phase IV consists in the development of WHO specifications for quality control and international trade.

Experimental huts constitute a crucial step for the WHOPES to assess a number of entomological criteria in different entomological settings [12]. A promising new tool must be effective against most, even all of the Anopheles vector populations. Indeed the industrial investment to manufacture massive numbers of LLINs is possible under condition of worldwide use. Given the patchy distribution of insecticide resistance mechanisms evolving in Anopheles vectors, their different phenotypic effect and the possible interactions, new products must be evaluated against vector populations bearing different resistance mechanisms before being labelled by the WHOPES.

In Côte d'Ivoire, two experimental stations, M'Bé and Yaokoffikro were built in the early 1990s close to Bouaké in the Bandama department [22]. In M'Bé, An. gambiae s.s population was known to be $95 \% \mathrm{M}$ form, $5 \% \mathrm{~S}$ form. The $k d r-w$ mutation was only present in the $S$ form at a frequency of $63 \%$ representing only $4 \%$ of the whole $A n$. gambiae population [23].

Until the political crisis in 2002 the An. gambiae population was susceptible to pyrethroids, organophosphates and carbamates. The only phenotypic resistance detected was to the dieldrin (cyclodiene organochlorine) and the fipronil (phenylpyrazole) [22]. In contrast, the An. gambiae population of Yaokoffikro was exclusively $S$ form $A n$. gambiae bearing the $k d r-w$ mutation at a very high frequency 95\% [22,23], until the political crisis.

The armed conflict led to a lot of population migration across the country, affecting social organization, economical and agricultural activities. At M'Bé, the rice-growing area of the West African Rice Development Association (WARDA, actually Africa Rice), it is unclear whether the crisis changed the local farming and Africa Rice practices that might have led to a shift in selection pressure. At the neighbouring WHOPES experimental hut station of Yaokoffikro, a recent study assessed the resistance status and showed the maintenance of high resistance to pyrethroids, DDT and carbamates in the An. gambiae s.s population, having both metabolic and target site mutation [24]. Ten years after the crisis, bioassays, biochemical and molecular analyses were conducted to update the resistance status in the An. gambiae s.s population from M’Bé.

\section{Methods \\ Study area}

This study was conducted in M'Bé valley $\left(5.209963^{\circ} \mathrm{W}\right.$, and $7.970241^{\circ} \mathrm{N}$ ) situated $30 \mathrm{~km}$ north of Bouaké in the central region of Côte d'Ivoire (Bandama department). M'Bé valley is a rice growing area where the Africa Rice, are conducting experimental field rice trials and where local farmers are also producing rice. The rice paddies are suitable breeding sites for mosquitoes especially for An. gambiae s.s. Experimental huts belonging to the "Institut Pierre Richet (IPR)" built in 1998 served over many years for the evaluation of different insecticides under the auspices of WHOPES [22,25-28]. Mosquito population in this area was composed by An. gambiae s.s, Anopheles funestus, Culex sp. and Mansonia sp. Anopheles gambiae s.s was mostly M molecular form and less resistant to pyrethroids and DDT bearing the Leu-Phe $k d r$ mutation (L1014F $k d r$ ) at an allelic frequency above 0.05 
$[8,22,23,25,29,30]$. Resistance to carbamates and organophosphates involving acetylcholinesterase insensitive has also been detected [28].

\section{Mosquito collections and maintenance}

During May 2012, larvae of An. gambiae s.s were collected in the rice paddies of the M'Bé rice growing area around the experimental field station and reared in IPR insectarium until emergence. The An. gambiae s.s Kisumu reference strain, which is free of any detectable resistance mechanisms, served as a susceptible control.

\section{Insecticide susceptibility tests}

Susceptibility bioassays on adult mosquitoes were conducted using WHO test kits [31]. Impregnated papers with diagnostic concentrations of 10 insecticide-active ingredients belonging to different chemical classes were prepared and tested as follows:

- Pyrethroids: permethrin (0.75\%), deltamethrin (0.05\%) and $\alpha$-cypermethrin $0.05 \%$;

- Pseudo-pyrethroid: etofenprox (0.05\%);

- Organochlorides: DDT (4\%) and dieldrin (4\%);

- Carbamates: carbosulfan (0.4\%) and bendiocarb (0.1\%);

- Organophosphates: fenitrothion (1\%) and the pirimiphos-methyl (1\%).

Filter papers were impregnated according to WHO specifications by the Centre de Recherche Entomologique de Cotonou (CREC) as described by Chandre et al. [32]. WHO tube tests were performed with batches of 25 unfed females of $A n$. gambiae s.s, two to three days old (four replicates per concentration). Mosquitoes were exposed to the insecticide-treated papers for $60 \mathrm{~min}$ at $25 \pm 2{ }^{\circ} \mathrm{C}$ and $80 \%$ relative humidity $(\mathrm{RH})$. The number of mosquitoes knocked down at regular intervals during the exposure period was scored and time to knock down 50\% and 95\% of the exposed mosquitoes (KDT50) and (KDT95) were determined. After the exposition period, mosquitoes were transferred to the observation tube of the test kit. They were supplied with $10 \%$ honey solution and held for $24 \mathrm{~h}$ before scoring mortality. Batches exposed to untreated papers were used as negative control.

In order to assess the involvement of detoxifying enzymes in the resistance phenotypes, complementary tests were performed with a $1 \mathrm{~h}$ pre-exposition to $\mathrm{PBO}$, an inhibitor of oxidases and esterases. Wild mosquito population was compared to a susceptible reference strain of An. gambiae s.s Kisumu. All control survival specimens (including the susceptible reference mosquito) from none exposed to insecticides were stored at $-80^{\circ} \mathrm{C}$ for biochemical analysis. The samples of mosquitoes exposed to different insecticides were kept at $-20^{\circ} \mathrm{C}$ for molecular analysis.
Identification of sibling species and Anopheles gambiae s.s $\mathrm{M}$ and $\mathrm{S}$ molecular forms

Ribosomal DNA was extracted from individual mosquitoes following Collins et al. [33] and used for PCR analysis to determine the species following Scott et al. [34] and the $\mathrm{M}$ and $\mathrm{S}$ molecular forms according to Favia et al. [35].

\section{PCR detection of the L1014F and L1014S $k d r$ and ace- $1^{R}$ mutations}

The presence of L1014F and L1014S $k d r$ alleles was assessed using hot oligonucleotide ligation assay (HOLA) technique according to the protocol of Lynd et al. [36]. The PCR-RFLP diagnostic test was used to detect the presence of G119S mutation (ace-1 gene) as described by Weill et al. [37].

\section{Biochemical analysis}

Biochemical assays were performed to compare the amount of mixed function oxidases (MFO), and the activity levels of non-specific esterases (NSE) for $\beta$ and $\alpha$-naphtyl acetate and glutathione S-transferases (GST) [38] in the wild $A n$. gambiae s.s. from M’Bé relative to the susceptible Kisumu strain. Mosquitoes used for the biochemical analysis had not been exposed to any insecticides prior to the assay.

\section{Data analysis}

WHO criteria [39] were adopted to define resistance status of the mosquito populations. When less than $80 \%$ mortality was observed the population was considered 'resistant'; between 80 and $97 \%$ mortality the population was considered 'tolerant' (or 'suspected of resistance' in the literature) and when the mortality was above $97 \%$ the population was considered 'susceptible'. Knockdown data were analyzed using the PoloPlus 1.0 software (LeOra Software). $\mathrm{KDT}_{50}$ and $\mathrm{KDT}_{95}$ were generated by means of a logtime probit model. The $\mathrm{KDT}_{50}$ and $\mathrm{KDT}_{95}$ generated were compared with that of the An. gambiae Kisumu reference susceptible strain by estimates of $\mathrm{KDT}_{50}$ and $\mathrm{KDT}_{95}$ ratios (RR).

Biochemical assay data (enzymatic activity per mg protein, levels of MFO, NSE and GST) of Kisumu and M'Bé An. gambiae s.s were compared using Mann-Whitney non-parametric $U$-test (Statistica software). Conformity of L1014F and L1014S $k d r$ and $a c e-1^{R}$ mutation frequencies with Hardy-Weinberg equilibrium was tested for An. gambiae s.s population from M'Bé using the exact probability test [40]. Statistical significance was set at the $5 \%$ level.

\section{Results}

\section{Bioassays}

\section{Knock-down effect}

The knock-down effects of organochlorides and pyrethroids on the An. gambiae s.s population from M'Bé compared to Kisumu strain are summarized in Table 1. 
The median knock-down time $\left(\mathrm{KDT}_{50}\right)$ ranged from 15.4 to $24.7 \mathrm{~min}$ and the $\mathrm{KDT}_{95}$ ranged from 19.5 to 39.5 min with the reference susceptible strain Kisumu. In contrast, the $\mathrm{KDT}_{50}$ ranged from 83.2 to 93.7 and the $\mathrm{KDT}_{95}$ ranged from 204.7 to 341.6 with the M'Bé $A n$. gambiae s.s. population. None of the M'Bé An. gambiae s.s mosquitoes were knocked down within the $60 \mathrm{~min}$ of contact with the DDT. These results indicate a strong resistance level illustrated by the resistant ratio $\left(R_{50}\right.$ and $R R_{95}$ ) ranging respectively from 3.8 to 5.1 and from 7.4 to 8.6 .

\section{Mortality}

The mortalities induced by all insecticides on An. gambiae s.s M'Bé (with and without a pre-exposition to PBO) are illustrated in Figure 1 (light bars). In the negative control, mortalities were always below 5\%. Diagnostic concentrations of all insecticides killed 99 or $100 \%$ of An. gambiae s.s Kisumu, the susceptible control, confirming the good quality of the impregnated papers.

All organochlorides (DDT and dieldrin), the carbamates (bendiocarb and carbosulfan) and the four pyrethroids (and pseudo-pyrethroids) killed less than $80 \%$ of $A n$. gambiae s.s. from M'Bé. Based on the WHO criteria, the An. gambiae s.s population from M'Bé is considered resistant to all insecticides cited above. It is interesting to note that the strongest resistance levels were observed with DDT (3.1\% mortality), dieldrin ( $21.8 \%$ mortality) and the carbosulfan (6.5\% mortality). The strongest resistance level observed with a pyrethroid insecticide was with permethrin (50.8\% mortality).
The organophosphates fenitrothion and pirimiphosmethyl killed respectively $95.2 \%$ and $98.1 \%$ of mosquitoes (Figure 1). Based on the WHO criteria, the An. gambiae s. $s$ population from M'Bé is considered susceptible to pirimiphos-methyl and tolerant to fenitrothion.

\section{Bioassays after a pre-exposition to $\mathrm{PBO}$}

When the An. gambiae s.s. mosquitoes from M'Bé displayed resistance to an insecticide, WHO bioassays were performed with a $1 \mathrm{~h}$ pre-exposition to $\mathrm{PBO}$. After preexposure to the $\mathrm{PBO} \alpha$-cypermethrin and deltamethrin induced $100 \%$ mortality indicating that resistance of An. gambiae s.s. from M'Bé to these pyrethroids relied exclusively on the oxidase and/or esterase activities (Figure 1, dark bars). With permethrin and etofenprox, the mortalities increased respectively from $34 \%$ and $51.2 \%$ to $63.3 \%$ and $89 \%$ indicating that the oxidase and esterase activities are largely involved in the resistance to these pyrethroids (or pseudo-pyrethroid) but are not responsible of the whole resistance. The same trend was observed with carbosulfan and bendiocarb (in a lesser extent). The mortalities respectively increased from $6.5 \%$ and $79.6 \%$ to $63.3 \%$ and $90.8 \%$ after pre-exposure to $\mathrm{PBO}$. In contrast the $\mathrm{PBO}$ did not largely increase the mortalities induced by the organochloride insecticides ( $3.1 \%$ to $13.3 \% \mathrm{Khi}^{2}=9.67$, $\mathrm{p}=0.002$ for DDT and $27.3 \%$ to $40.8 \%$; $\mathrm{Khi}^{2}=3.22, \mathrm{p}=$ 0.074 for dieldrin) indicating that MFO and NSE are not (or slightly involved) responsible for the major part of resistance.

The same trend was observed with $\alpha$-cypermethrin, deltamethrin with a decrease of both $\mathrm{KDT}_{50}$ and $\mathrm{KDT}_{95}$

Table 1 Knock-down time of Anopheles gambiae s.s from M'Bé exposed to pyrethroids and DDT relative to the reference Kisumu Anopheles gambiae s.s strain

\begin{tabular}{|c|c|c|c|c|c|c|}
\hline Insecticide & Strain & $\mathbf{N}$ & $\mathrm{KdT}_{50}\left(\mathrm{Cl}_{95}\right)$ & $\mathrm{KdT}_{95}(\min )$ & $\mathrm{RR}_{50}$ & $\mathbf{R R}_{\mathbf{9 5}}$ \\
\hline \multirow[t]{2}{*}{ DDT 4\% } & Kisumu & 101 & $15.4(12.8-18.5)$ & $19.5(14.1-27.1)$ & - & - \\
\hline & M'Bé & 193 & NA & NA & NA & NA \\
\hline$D D T 4 \%+P B O$ & M'Bé & 105 & $N A$ & $N A$ & $N A$ & $N A$ \\
\hline \multirow[t]{2}{*}{ Permethrin $0.75 \%$} & Kisumu & 101 & $17.3(16.3-18.4)$ & $23.9(21.8-28.1)$ & - & - \\
\hline & M'Bé & 201 & 83.1 (73.9-99.2) & $204.7(155.7-313.7)$ & $4.8(4.1-5.6)$ & $8.6(6.0-12.2)$ \\
\hline Permethrin $0.75 \%+P B O$ & M'Bé & 100 & $94.9(76.2-134.7)$ & $469.9(276.8-1$ 146.7) & $5.5(4.1-7.2)$ & $19.6(9.9-38.5)$ \\
\hline \multirow[t]{2}{*}{ a-cypermethrin $0.05 \%$} & Kisumu & 99 & $17.8(12.9-22.8)$ & $39.1(29.2-74.1)$ & - & - \\
\hline & M'Bé & 197 & $90.3(75.5-118.9)$ & $341.6(224.3-673.1)$ & $5.1(4.2-6.1)$ & $8.7(5.7-13.3)$ \\
\hline a-cypermethrin $0.05 \%+P B O$ & M'Bé & 106 & $28(26.4-29.6)$ & $59.4(54.3-66.4)$ & $1.6(1.4-1.7)$ & $1.5(1.3-1.8)$ \\
\hline \multirow[t]{2}{*}{ Deltamethrin $0.05 \%$} & Kisumu & 126 & $19.6(16.8-22.5)$ & $37.4(31.3-50.4)$ & - & - \\
\hline & M'Bé & 208 & $83.2(73.6-98.3)$ & $274.9(205.5-415.4)$ & $4.2(3.6-4.9)$ & $7.4(5.1-10.5)$ \\
\hline Deltamethrin $0.05 \%+P B O$ & M'Bé & 103 & $41.4(37.9-45.7)$ & $99.1(81.7-133.3)$ & $2.1(1.9-2.3)$ & $2.6(2.2-3.2)$ \\
\hline \multirow[t]{2}{*}{ Etofenprox $0.5 \%$} & Kisumu & 105 & $24.7(21.9-27.5)$ & $39.5(34.4-49.7)$ & - & - \\
\hline & M'Bé & 200 & $93.7(80.7-116.9)$ & 296.5 (210.7-499.4) & $3.8(3.1-4.6)$ & $7.5(4.9-11.5)$ \\
\hline Etofenprox $0.5 \%+P B O$ & M'Bé & 91 & $83.2(65.7-139.2)$ & 265.1 (152.7-989.6) & $3.4(2.7-44.2)$ & $6.7(3.9-11.5)$ \\
\hline
\end{tabular}

$C l$ : confidence interval; $K D T$ : knock-down time; $K D T_{50}$ : time taken for $50 \%$ of the test mosquitoes to be knocked down; $K D T_{95}$ : time taken for $95 \%$ of the test mosquitoes to be knocked down; RR: knock-down time ratio (KDT 50 of the tested population/KDT ${ }_{50}$ of the susceptible Kisumu strain); $N A$ : not available. 


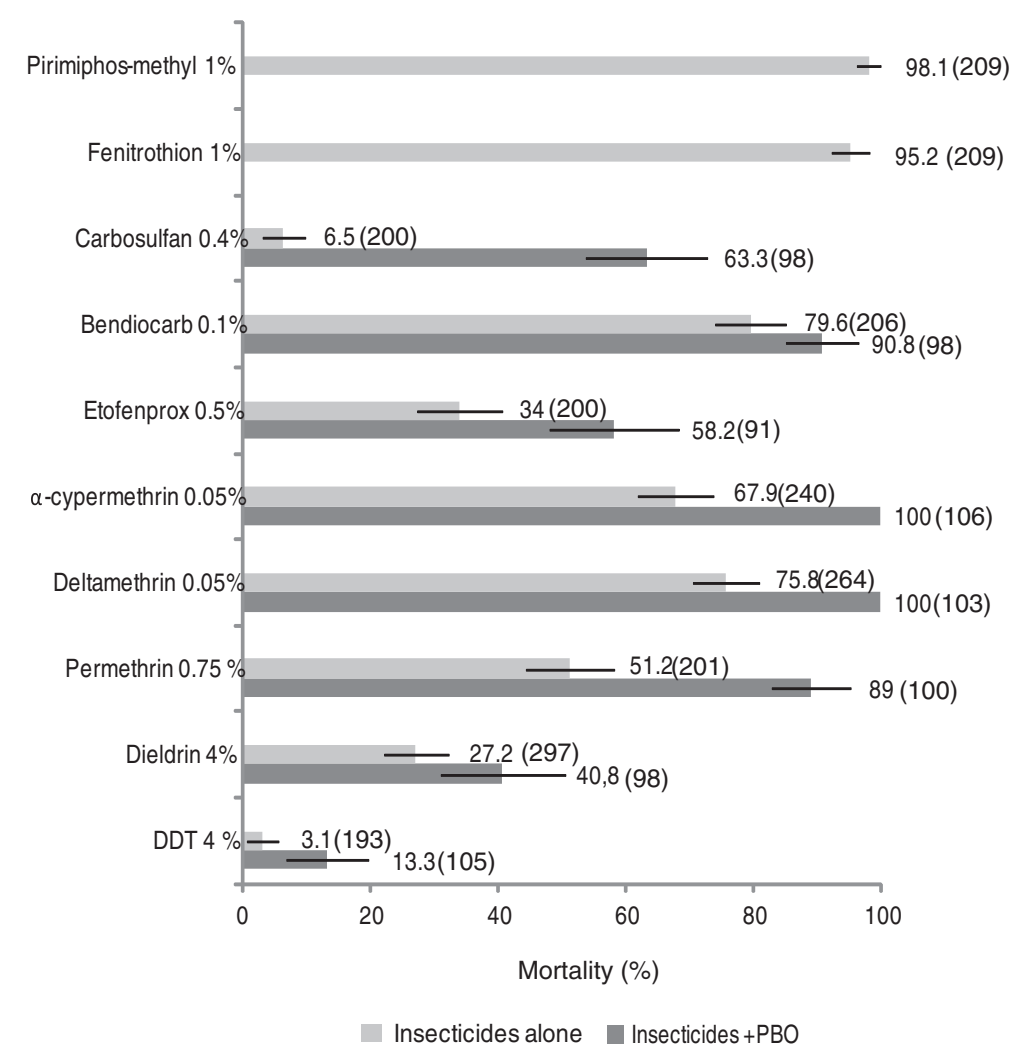

Figure 1 Insecticidal effects of diagnostic concentrations of insecticides (60 min contact in WHO tube tests) with or without a 60 min pre-exposition to $\mathrm{PBO}$.

reducing significantly the $R_{50}$ (respectively from 5.1 and 4.2 to 1.6 and 2.1) and $R R_{95}$ (respectively from 8.8 and 7.4 to 1.5 and 2.6). The decrease of the RR50 and RR95 with etofenprox was not significant (respectively 3.8 and 7.5 to 3.4 and 6.7 with overlapping confidence intervals). Surprisingly whereas the $\mathrm{PBO}$ pre-exposition increased the mortality induced by permethrin, it did not decrease the $\mathrm{KDT}_{50}$ and $\mathrm{KDT}_{95}$.

\section{Molecular and biochemical analyses}

Among the 226 mosquitoes, three specimens were $A n$. gambiae s.s S form, corresponding to $1.3 \%$ of the population. Neither ace- $1^{R}$ mutation nor the $k d r-e$ mutation (L1014S) were detected in the M'Bé population sample (Table 2). Concerning the $k d r-w$ mutation (L1014F), the genotypes were distributed as follow among the $\mathrm{M}$-form An. gambiae: 16 were resistant homozygotes (RR), 114 were heterozygotes (RS), and 93 were susceptible homozygotes (SS). The $k d r-w$ frequency was 0.33 . The three S-form specimens were respectively SS, RS and RR.

Table 2 shows the mean amount of MFO, and mean activities of NSE and GST of An. gambiae s.s from M'Bé relative to the susceptible reference Kisumu strain. The mean NSE respectively $\alpha$ and $\beta$-esterases activities (respectively 0.155 and 0.125$)$ and MFO (0.198) level were significantly higher in An. gambiae s.s from M'Bé than in the Kisumu specimens (respectively 0.086 and 0.084 for $\alpha$ and $\beta$-esterases, and 0.095 for MFO) $(\mathrm{P}<0.001)$. The level of GST activities did not differ significantly between the samples from M'Bé (0.378) than from Kisumu samples (0.295; P > 0.05).

Table 2 Genotype frequencies of the $k d r$, ace- 1 locus and mean level of NSE, MFO and GST activity in Anopheles gambiae s.s. Kisumu and M'Bé

\begin{tabular}{|c|c|c|}
\hline & Kisumu & M'Bé \\
\hline$F(k d r-w)$ & - & $0.33(226)$ \\
\hline$F(k d r-e)$ & - & $0.00(226)$ \\
\hline $\mathrm{F}\left(\right.$ ace $\left.-1^{R}\right)$ & - & $0.00(226)$ \\
\hline$a-N a$ & $0.086 \pm 0.007^{a}(40)$ & $0.155 \pm 0.012^{b}(40)$ \\
\hline$\beta-\mathrm{Na}$ & $0.084 \pm 0.007^{a}(40)$ & $0.125 \pm 0.017^{\mathrm{b}}(40)$ \\
\hline MFO & $0.095 \pm 0.008^{a}$ & $0.198 \pm 0.020^{b}(36)$ \\
\hline GST & $0.295 \pm 0.032^{\mathrm{a}}(40)$ & $0.378 \pm 0.085^{\mathrm{a}}(40)$ \\
\hline
\end{tabular}

$a$-Na: NSE activity with substrate alpha-naphthyl acetate ( $\mu$ mol $\alpha$-naphthol produced $/ \mathrm{min} / \mathrm{mg}$ protein).

$\beta$-Na: NSE level with substrate beta-naphthyl acetate $(\mu \mathrm{mol} \beta$-naphthol produced $/ \mathrm{min} / \mathrm{mg}$ protein).

MFO: MFO level (nmol equivalent unit of cytochrome P450/mg protein). GST: GST level (nmol GSH conjugated/min/mg protein).

(): Number tested of Anopheles gambiae s.s. females.

Different letter superscripts indicates enzyme level significantly higher than with the Kisumu susceptible An. gambiae s.s. strain $(P<0.05)$. 


\section{Discussion}

Ten years after the armed conflict in Côte d'Ivoire, the resistance status of the An. gambiae s.s population from M'Bé station has been updated in order to have background knowledge to restart the pesticide evaluation activities in the context of the ABC Network. Historically, M'Bé was considered an insecticide-susceptible $A n$. gambiae s.s population. Indeed until the political crisis in 2002, the An. gambiae s.s population was susceptible to pyrethroids, organophosphates and carbamates. The only phenotypic resistance detected was to dieldrin (organochloride) and fipronil (phenylpyrazole) [22]. In the present study, the M'Bé An. gambiae s.s population was resistant to organochlorides, pyrethroids, carbamates and is 'tolerant' to organophosphates. Bioassays with a pre-exposition to $\mathrm{PBO}$, an inhibitor of esterases and oxidases, evidenced the strong involvement of these enzyme families in the resistant phenotypes. With the molecular and biochemical assays two types of resistance mechanisms were identified: 1$)$ the $k d r$ - $w$ target site mutation with a relatively low frequency $(0.33)$; and, 2) the over-activities of MFO and NSE. In contrast, neither $k d r$-e nor ace- $1^{R}$ mutations were detected in the M'Bé population. Moreover GST did not display over activity.

These striking results exerted the rapid evolution of the resistance mechanisms among An. gambiae s.s populations in such environment. Further investigation must be conducted in order to understand the changes in agricultural practices or socio-economic context that might explain the shift from a susceptible to strongly resistant population. The only well-known agricultural pressure in this area is the treatment of the rice paddies with deltamethrin-based product by AfricaRice (Ahoua Alou, pers comm). The practices of the local farmers are not available yet. This agricultural selective pressure might have been involved in the resistance mechanisms as already showed in several countries [9,41-43]. Moreover the automatic distribution of LLINs to pregnant women and children under five, since 2006, and the implementation of the universal coverage with LLINs launched recently might have added a supplementary selective pressure [44]. Indeed evidences of the selective pressures induced by the massive use of LLINs are more and more documented $[7,45]$.

The distribution of the $k d r-w$ genotypes showed that only $7.5 \%$ of $A n$. gambiae s.s were homozygote resistant. This mutation is well known to be recessive. This suggests that the impact of the $k d r-w$ mutation on the phenotypic resistance is relatively low. This was confirmed by the PBO pre-exposure bioassays during which most of the insecticides recovered a high efficacy.

NSE and MFO seem to be responsible for most of the phenotypic resistance in this An. gambiae s.s population. The specific genes of NSE and MFO will have to be identified using gene expression or proteomic tools to determine if they correspond to genes already suspected in pyrethroid resistance or if these are new genes [46].

The results showed carbamate resistance in An. gambiae s.s population from M'Bé, whilst only a high level of mortality was found with organophosphate. The absence of cross-resistance to carbamates and to organophosphates is confirmed by the absence of the ace-1 G119S mutation, despite N'Guessan et al. [28] reported reduction of the acetylcholinesterase activities in the M'Bé An. gambiae s.s population in 2003. In this study N'Guessan et al. did not search for the ace- $1^{R}$ mutation. In the present study, the absence of the ace-1 G119S mutation in M'Bé An. gambiae s.s population associated with the resistance to carbamate strongly supports the involvement of metabolic resistance based on the high activities of NSE or MFO and the significant increase of mortalities using the synergist PBO. The involvement of NSE and MFO at M'Bé in An. gambiae $\mathrm{M}$ molecular form was also reported in the field experimental station of Pitoa (Cameroon), where greater oxidase and esterase activities were observed in An. gambiae s.s [47-49] and where $k d r$ and $a c e-1^{R}$ were also absent. In contrast, in Yaokoffikro the field experimental hut station in Côte d'Ivoire, $40 \mathrm{~km}$ from M'Bé, greater GST and esterase activities were observed in $A n$. gambiae s.s associated with high frequencies of L1014F $k d r(0.94)$ and $a c e-1^{R}(0.50)$ mutations, but in this place $100 \%$ of mosquitoes belong to the $S$ form [24].

This new results highlight once again the high variability in insecticide resistance patterns and evolution processes driving the resistance mechanisms evolution among malaria vectors. In terms of vector control research and vector control tool development, it appears crucial to take into account these different ecological patterns and evolution processes. The M'Bé $A n$. gambiae s.s population is currently one of the rare $A n$. gambiae s.s population in west Africa bearing the $k d r-w$ mutation at relatively low frequency (0.33). It offers a unique opportunity to deeply study the impact of such metabolic mechanisms on resistance phenotypes. Undergoing program aims to describe and select enzymatic mechanisms involved in resistance phenotype specific to the main insecticide families used for public health (organochlorides, pyrethroids, carbamates and organophosphates).

In the context of alternative vector control tool development, the M'Bé station will allow scientists to study and quantify the benefit to use chemicals combinations or new active ingredient to control An. gambiae s.s vectors bearing different mechanisms in the same area. It is especially rare and important to evaluate the efficacy of vector control tools in development against $A n$. gambiae s.s bearing metabolic mechanisms without the $k d r-w$ mutation. 


\section{Conclusion}

In a 10-year period, the An. gambiae s.s population of M'Bé area shifted from susceptibility to high resistance to three insecticide families usually used in public health control programmes (organochlorides, pyrethroids, carbamates) except the fourth one (organophosphates). The resistance pattern is unusual and offers an ideal context for further investigation on the interaction and evolution processes of metabolic resistance and $k d r-w$ target site mutation. Trials to evaluate their impact on the protective efficacy of malaria control interventions, as well as new tools in development to manage these complex mechanisms, are urgently needed.

\section{Abbreviations \\ LLINs: Long-lasting insecticidal nets; IRS: Indoor residual spraying; WHOPES: World Health Organization Pesticide Evaluation Scheme; IPR: Institut Pierre Richet; L1014F kdr: Leucine-phenylalanine knockdown resistance; L1014S kdr: Leucine-serine knock-down resistance; ace- $1^{R}$ : Acetylcholinesterase-1 resistance; ace-1 G119S: G199S mutation in ace-1; NSE: Non-specific esterase; MFO: Mixed-function oxidase; GST: Glutathione S- transferase; PCR: Polymerase chain reaction; DDT: Dichloro-diphenyl- trichloroethane; R: Resistant; S: Susceptible; GSH: Reduced form of glutathione; RH: Relative humidity. \\ Competing interests \\ The authors declare that they have no competing interests. \\ Authors' contributions \\ AAK, FC and CP designed the study. AAK, LPAA and AMA supervised and conducted the field work. LPAA conducted the laboratory work. AAK and LPAA drafted the paper. CP and FC critically revised the manuscript. All authors read and approved the final manuscript.}

\section{Acknowledgements}

The study has been financially supported by the Institut de Recherche pour le Développement through the research network "Anopheles Biology and Control" (ABC Network). The ABC Network is an integral part of the WHO Collaborating Centre for pesticide evaluation in public health. We are very grateful to all the staff at the Institut Pierre Richet, Bouaké, Côte d'Ivoire and Centre de Recherche Entomologique de Cotonou, Benin, for their hard work during the field and laboratory experiments. Special thanks also go to Aboubacar Koné, Jean-Paul Kabran Kouamé and Aboubacar Sidick for technical assistance.

\section{Author details}

${ }^{1}$ Institut Pierre Richet (IPR), Abidjan BP 47, Côte d'Ivoire. 'Laboratoire de Zoologie et Biologie Animale, Université Felix Houphouët-Boigny de Cocody, Abidjan 22 BP 582, Côte d'Ivoire. ${ }^{3}$ Institut de Recherche pour le Développement (IRD)/UMR224 MiVEGEC, Montpellier 34394, France. ${ }^{4}$ Centre de Recherche Entomologique de Cotonou, Cotonou 06 BP 2604, Bénin.

\section{Received: 30 November 2012 Accepted: 26 April 2013}

Published: 4 May 2013

\section{References}

1. RBM: Technical support network for insecticide-treated netting materials: scaling-up insecticide-treated netting programmes in Africa. In A strategic framework for coordinated national action. Edited by Roll Back Malaria. Geneva: WHO; 2002:14.

2. WHO: Pesticides and their application for the control of vectors and pests of public health importance. Geneva: WHO/CDS/NTD/WHOPES/GCDPP/2006.1; 2006.

3. Zaim M, Aitio A, Nakashima N: Safety of pyrethroid-treated mosquito nets. Med Vet Entomol 2000, 14:1-5.

4. Akogbeto MC, Djouaka R, Noukpo H: Utilisation des insecticides agricoles au Bénin. Bull Soc Pathol Exot 2005, 98:400-405.
5. Yadouleton AW, Padonou G, Asidi A, Moiroux N, Bio-Banganna S, Corbel V, N'Guessan R, Gbenou D, Yacoubou I, Gazard K, Akogbeto MC: Insecticide resistance status in Anopheles gambiae in southern Benin. Malar J 2010, 9:83.

6. Czeher C, Labbo R, Arzika I, Duchemin JB: Evidence of increasing Leu-Phe knockdown resistance mutation in Anopheles gambiae from Niger following a nationwide long-lasting insecticide-treated nets implementation. Malar J 2008, 7:189.

7. Trape JF, Tall A, Diagne N, Ndiath O, Ly AB, Faye J, Dieye-Ba F, Roucher C, Bouganali C, Badiane A, Sarr FD, Mazenot C, Touré-Baldé A, Raoult D, Druilhe P, Mercereau-Puijalon O, Rogier C, Sokhna C: Malaria morbidity and pyrethroid resistance after the introduction of insecticide-treated bednets and artemisinin-based combination therapies: a longitudinal study. Lancet Infect Dis 2011, 11:925-932.

8. Chandre F, Darrier F, Manga L, Akogbeto M, Faye O, Mouchet J, Guillet P. Status of pyrethroid resistance in Anopheles gambiae sensu lato. Bull World Health Organ 1999, 77:230-234.

9. Dabire KR, Diabate A, Djogbenou L, Ouari A, N'Guessan R, Ouedraogo JB, Hougard JM, Chandre F, Baldet T: Dynamics of multiple insecticide resistance in the malaria vector Anopheles gambiae in a rice growing area in South-Western Burkina Faso. Malar J 2008, 7:188.

10. Santolamazza F, Calzetta M, Etang J, Barrese E, Dia I, Caccone A, Donnelly MJ, Petrarca V, Simard F, Pinto J, della Torre A: Distribution of knock-down resistance mutations in Anopheles gambiae molecular forms in west and west-central Africa. Malar J 2008, 7:74.

11. Ranson H, Abdallah H, Badolo A, Guelbeogo WM, Kerah-Hinzoumbe C, Yangalbe-Kalnone E, Sagnon N, Simard F, Coetzee M: Insecticide resistance in Anopheles gambiae: data from the first year of a multi-country study highlight the extent of the problem. Malar J 2009, 8:299.

12. Hemingway J, Beaty BJ, Rowland M, Scott TW, Sharp BL: The Innovative Vector Control Consortium: improved control of mosquito-borne diseases. Trends Parasitol 2006, 22:308-312.

13. The malERA Consultative Group on Vector Control: A research agenda for malaria eradication: vector control. PLOS Med 2011, 8:e1000401.

14. Hougard JM, Corbel V, N'Guessan R, Darriet F, Chandre F, Akogbeto M, Baldet T, Guillet P, Carnevale P, Traoré-Lamizana M: Efficacy of mosquito nets treated with insecticide mixtures or mosaics against insecticide resistant Anopheles gambiae and Culex quinquefasciatus (Diptera: Culicidae) in Cote d'Ivoire. Bull Entomol Res 2003, 93:491-498.

15. Pennetier C, Costantini C, Corbel V, Licciardi S, Dabire RK, Lapied B, Chandre F, Hougard JM: Mixture for controlling insecticide-resistant malaria vectors. Emerg Infect Dis 2008, 14:1707-1714.

16. Pennetier C, Costantini C, Corbel V, Licciardi S, Dabire RK, Lapied B, Chandre F, Hougard JM: Synergy between repellents and organophosphates on bed nets: efficacy and behavioural response of natural free-flying An. gambiae mosquitoes. PLoS One 2009, 4:e7896.

17. Oxborough RM, Kitau J, Matowo J, Feston E, Mndeme R, Mosha FW, Rowland M: ITN mixtures of chlorfenapyr (pyrrole) and alphacypermethrin (pyrethroid) for control of pyrethroid resistant Anopheles arabiensis and Culex quinquefasciatus. PLoS One 2013, 8(2):e55781.

18. Corbel V, Chabi J, Dabire RD, Etang J, Nwane P, Pigeon O, Akogbeto M, Hougard JM: Field efficacy of a new mosaic long-lasting mosquito net (PermaNet 3.0) against pyrethroid-resistant malaria vectors: a multicentre study in Western and Central Africa. Malar J 2010, 9:113.

19. N'Guessan R, Asidi A, Boko P, Odjo A, Akogbeto M, Pigeon O, Rowland M: An experimental hut evaluation of PermaNet $^{\oplus} 3.0$, a deltamethrinpiperonyl butoxide combination net, against pyrethroid-resistant Anopheles gambiae and Culex quinquefasciatus mosquitoes in southern Benin. Trans R Soc Trop Med Hyg 2010, 104:758-765.

20. Tungu PK, Magesa S, Maxwell C, Masue D, Sudi W, Myamba J, Rowland M: Evaluation of PermaNet ${ }^{\oplus} 3.0$ LN against Anopheles gambiae and Culex quinquefasciatus in experimental huts in Tanzania. London, UK: National Institute for Medical Research ARC, Muheza, Tanzania and London School of Hygiene and Tropical Medicine; 2008.

21. Koudou BG, Koffi AA, Malone D, Hemingway J: Efficacy of PermaNet ${ }^{\circledR} 2.0$ and PermaNet ${ }^{\oplus} 3.0$ against insecticide-resistant Anopheles gambiae in experimental huts in Cote d'Ivoire. Malar J 2011, 10:172.

22. Darriet F, N'Guessan R, Hougard JM, Traoré-Lamizana M, Carnevale P: Un outil expérimental indispensable à l'évaluation des insecticides: les cases-pièges. Bull Soc Pathol Exot 2002, 95:299-303. 
23. Chandre F, Manguin S, Brengues C, Dossou Yovo J, Darriet F, Diabate A, Carnevale P, Guillet P: Current distribution of a pyrethroid resistance gene $(k d r)$ in Anopheles gambiae complex from West Africa and further evidence for reproductive isolation of the Mopti form. Parassitologia 1999, 41:319-322.

24. Koffi AA, Ahoua Alou LP, Adja MA, Kone M, Chandre F, N'Guessan R: Update on resistance status of Anopheles gambiae s.s. to conventional insecticides at a previous WHOPES field site, "Yaokoffikro", 6 years after the political crisis in Cote d'Ivoire. Parasit Vectors 2012, 5:68.

25. Darriet F, N' guessan R, Koffi AA, Konan L, Doannio JMC, Chandre F, Carnevale P: [Impact of the resistance to pyrethroids on the efficacy of impregnated bednets used as a means of prevention against malaria: results of the evaluation carried out with deltamethrin SC in experimental huts](in French). Bull Soc Pathol Exot 2000, 93:131-134.

26. Darriet $F, N^{\prime} G$ uessan $R$, Carnevale P: Evaluations en cases-pièges de l'effet protecteur de moustiquaires non imprégnées d'insecticide dans la prévention des piqûres d'Anopheles gambiae s.s. Sante 2000, 10:413-417.

27. Koffi AA, Darriet F, N'Guessan R, Doannio JM, Carnevale P: Évaluation au laboratoire de l'efficacité insecticide de l'alpha-cyperméthrine sur les populations d'Anopheles gambiae de Côte d'Ivoire résistantes à la perméthrine et à la deltaméthrine. Bull Soc Pathol Exot 1999, 92:62-66.

28. N'Guessan R, Darriet F, Guillet P, Carnevale P, Traore-Lamizana M, Corbel V, Koffi AA, Chandre F: Resistance to carbosulfan in Anopheles gambiae from Ivory Coast, based on reduced sensitivity of acetylcholinesterase. Med Vet Entomol 2003, 17:19-25.

29. della Torre A, Fanello C, Akogbeto M, Dossou-yovo J, Favia G, Petrarca V Coluzzi M: Molecular evidence of incipient speciation within Anopheles gambiae s.s. in West Africa. Insect Mol Biol 2001, 10:9-18.

30. della Torre A, Tu Z, Petrarca V: On the distribution and genetic differentiation of Anopheles gambiae s.s. molecular forms. Insect Biochem Mol Biol 2005, 35:755-769.

31. WHO: Guidelines for testing mosquito adulticides intended for Indoor Residual Spraying (IRS) and Insecticide Treated Nets (ITNs). Geneva: WHO/CDS/NTD/ WHOPES/GCDDP/2006.3; 2006.

32. Chandre F, Darriet F, Manguin S, Brengues C, Carnevale P, Guillet P: Pyrethroid cross resistance spectrum among populations of Anopheles gambiae s.s. from Cote d'Ivoire. J Am Mosq Control Assoc 1999, 15:53-59.

33. Collins FH, Finnerty V, Petrarca V: Ribosomal DNA-probes differentiate five cryptic species in the Anopheles gambiae complex. Parassitologia 1988, 30:231-240.

34. Scott JA, Brogdon WG, Collins FH: Identification of single specimens of the Anopheles gambiae complex by the polymerase chain reaction. AmJTrop Med Hyg 1993, 49:520-529.

35. Favia G, Lanfrancotti A, Spanos L, Siden Kiamos I, Louis C: Molecular characterization of ribosomal DNA polymorphisms discriminating among chromosomal forms of Anopheles gambiae s.s. Insect Mol Biol 2001, 10:19-23.

36. Lynd A, Ranson H, McCall PJ, Randle NP, Black WC, Walker ED, Donnelly MJ: A simplified high-throughput method for pyrethroid knock-down resistance ( $k d r)$ detection in Anopheles gambiae. Malar J 2005, 4:16.

37. Weill M, Malcolm C, Chandre F, Mogensen K, Berthomieu A, Marquine M, Raymond M: The unique mutation in ace-1 giving high insecticide resistance is easily detectable in mosquito vectors. Insect Mol Biol 2004, 13:1-7.

38. WHO: Techniques to detect resistance mechanisms (Field and laboratory manual). Geneva: WHO/CDS/CPC/MAL/98.6; 1998.

39. WHO: Tests procedures for insecticide resistance monitoring in malaria vectors, bioefficacy and persistence of insecticides on treated surfaces. Geneva: WHO/ CDS/CPC/MAL/98.12; 1998

40. Raymond M, Rousset F: GENEPOP (Version 1.2): a population genetics software for exact tests and ecumenicism. J Heredity 1995, 86:248-249.

41. Yadouleton A, Martin T, Padonou G, Chandre F, Asidi A, Djogbenou L, Dabire R, Aikpon R, Boko M, Glitho I, Akogbeto M: Cotton pest management practices and the selection of pyrethroid resistance in Anopheles gambiae population in northern Benin. Parasit Vectors 2011, 4:60.

42. Konan KG, Koné AB, Konan YL, Fofana D, Konan KL, Diallo A, Ziogba JC, Touré M, Kouassi KP, Doannio JM: Résistance d'Anopheles gambiae s.l. aux pyréthrinoïdes et au DDT à Tiassalékro, village de riziculture irriguée en zone sud forestière de Côte-d'Ivoire. Bull Soc Pathol Exot 2011, 104:303-306.
43. Bigoga JD, Ndangoh DN, Awono-Ambene PH, Patchoke S, Fondjo E, Leke RG: Pyrethroid resistance in Anopheles gambiae from the rubber cultivated area of Niete, South Region of Cameroon. Acta Trop 2012 124:210-214.

44. Doudou DT, Assi SB, Monnet AM, Diobo Doudou S, AMOIKON MI, Boza GS, Koffi SK: In Evaluation de la couverture en MIl et des connaissances, attitudes et pratiques (CAP) des ménages relatives à l'utilisation des MII dans les districts sanitaires de la Côte d'lvoire. Edited by CRD. Bouaké: Université de Bouaké; 2009:79

45. Corbel V, Akogbeto M, Damien GB, Djenontin A, Chandre F, Rogier C, Moiroux N, Chabi J, Banganna B, Padonou GG, Henry MC: Combination of malaria vector control interventions in pyrethroid resistance area in Benin: a cluster randomised controlled trial. Lancet Infect Dis 2012, 12:617-626

46. Ranson H, N'Guessan R, Lines J, Moiroux N, Nkuni Z, Corbel V: Pyrethroid resistance in African anopheline mosquitoes: what are the implications for malaria control? Trends Parasitol 2011, 27:91-98.

47. Etang J, Manga L, Toto JC, Guillet P, Fondjo E, Chandre F: Spectrum of metabolic-based resistance to DDT and pyrethroids in Anopheles gambiae s.l. populations from Cameroon. J Vector Ecol 2007, 32:123-133.

48. Chouaibou M, Etang J, Brevault T, Nwane P, Hinzoumbe CK, Mimpfoundi R, Simard F: Dynamics of insecticide resistance in the malaria vector Anopheles gambiae s.l. from an area of extensive cotton cultivation in Northern Cameroon. Trop Med Int Health 2008, 13:476-486.

49. Chouaibou M, Simard F, Chandre F, Etang J, Darriet F, Hougard JM: Efficacy of bifenthrin-impregnated bednets against Anopheles funestus and pyrethroid-resistant Anopheles gambiae in North Cameroon. Malar J 2006, $5: 77$.

doi:10.1186/1475-2875-12-151

Cite this article as: Koffi et al:: Insecticide resistance status of Anopheles gambiae s.s population from M'Bé: a WHOPES-labelled experimental hut station, 10 years after the political crisis in Côte d'Ivoire. Malaria Journal $201312: 151$.

\section{Submit your next manuscript to BioMed Central and take full advantage of:}

- Convenient online submission

- Thorough peer review

- No space constraints or color figure charges

- Immediate publication on acceptance

- Inclusion in PubMed, CAS, Scopus and Google Scholar

- Research which is freely available for redistribution 